\title{
Design of a Wireless Communication Drip Irrigation System using nRF24L01 Technology
}

\author{
Joseph Azeta*1, Christian A. Bolu ${ }^{1}$, Famous Alele ${ }^{1}$, Emmanuel O. Daranijo ${ }^{1}$ \\ ${ }^{1}$ Department of Mechanical Engineering, Covenant University, Ota, Ogun state, Nigeria.
}

\begin{abstract}
:
In the application of traditional irrigation methods, water saving is not considered. Due to the fact that the water is irrigated directly on the land, crops sometimes undergo increased stress from disparities in the soil moisture, consequently crop performance and output is reduced. This paper discusses an automated drip irrigation system designed to operate based on soil moisture content as detected by soil moisture sensors. The data from the sensors are analyzed and acted upon based on the software (code) loaded onto the microcontrollers. In this system, a microcontroller is assigned each row of crops. Each microcontroller obtains the mean soil moisture from an array of moisture sensors spread across the row. The resultant reading is wirelessly transmitted to and receiver by another microcontroller with the aid of nRF24L01 transceivers. A water reservoir tank of capacity 1000 liters elevated on a stanchion of height 2 meters above the ground is used to store and supply water at the required pressure via gravity to the drip irrigation system when required. The components, design, programming, working, and performance of the circuit are described in this article.
\end{abstract}

Keywords: Wireless communication, drip irrigation, Microcontroller, soil moisture sensors, nRF24L01 transceivers.

\section{INTRODUCTION}

Irrigation is the process of artificially supplying water to land or soil. It is used to aid in the growth and development of agricultural crops, revegetation of damaged soils in dry areas, maintenance of landscapes, and during periods of insufficient rainfall [1]. Irrigation of crops is a significantly time-expending activity; to be done in a feasible amount of time, it also demands a huge amount of human resources. Conventionally, all labour required in the irrigation process were carried out by humans [2]. Also, the cost of labour is on the increase. As a result of this, if efforts are not invested into the optimization of these resources, additional money will be required by the same processes. In the application of traditional irrigation methods, water saving is not considered. Due to the fact that the water is irrigated directly on the land, crops sometimes undergo increased stress from disparities in the soil moisture, consequently crop performance and output is reduced. The absence of an appropriate water control system results in improper use and wastage of water [3]. Majority of farmers irrigate using manual means which can be said to be effective for small scale farming. But the larger the farmland, the greater the need for a more efficient and effective means of irrigation, hence, an automated irrigation system [4].

Automated irrigation systems are one of the most efficient, effective and convenient technique of water optimization. The systems help in conserving water and reducing wastage, thereby enabling more land to be put under irrigation. Furthermore, a controlled irrigation will make possible all yearround farming of crops. Also, crops cultivated under controlled conditions have a tendency to be healthier. This means that more and better yields are harvested all throughout the year.

A method for more efficient irrigation and uses of water is the use of soil moisture sensors to control the irrigation process. Soil moisture sensors can measure the soil water content, allowing us to detect when soil moisture drops below the required. This makes it possible to automatically turn on the irrigation when required. This maintains a well irrigated field whilst reducing water wastage [5]. The communication module is a very sensitive and vital part, especially for large scale projects, of an automated irrigation system. It ensures that accurate real time data is wirelessly transmitted from the sensing modules and received by the actuating modules of the irrigation system. Most small-scale projects (10m2 or less) make use of Bluetooth as the communication device, especially because they are easy to operate and work with [6, 7, 8]. Much larger project makes use of internet or Wi-Fi communication, using modules such as the ESP8266-01, NodeMCU, etc., thereby allowing for communication over long distances $[9,10$, $11,12]$.

This paper discusses an automated drip irrigation system designed to operate based on soil moisture content as detected by soil moisture sensors. The data from the sensors are analyzed and acted upon based on the software (code) loaded onto the microcontrollers. In this system, a microcontroller is assigned each row of crops. Each microcontroller obtains the mean soil moisture from an array of moisture sensors spread across the row. The resultant reading is wirelessly transmitted to a receiver by another microcontroller with the aid of nRF24L01 transceivers. This microcontroller programmed to maintain a predetermined soil moisture range as required for each type of crop. The nRF24L01 transceivers are used in this project because can operate over long ranges (up to $100 \mathrm{~m}$ ) and they achieve this without the need for internet $[13,14,15]$. The 
$\mathrm{NRF}$ is a small size radio frequency wireless transceiver. It is a very useful component for wireless projects because it is userfriendly, affordable, has good range and low power consumption. The module operates on a permit-free $2.4 \mathrm{G}$ ISM band and reaches a data speed of up to $2 \mathrm{Mbps}$. The module can use 125 different channels to have a network of 125 modems working independently in one place. Each channel may have up to six addresses, or each unit may communicate simultaneously with up to six other units. This creates the possibility of creating a medium-scale network without the need for internet or Wi-Fi. This module's power consumption during transmission is only around $12 \mathrm{~mA}$, which is lower than a single LED. The module's operating voltage is from 1.9 to $3.6 \mathrm{~V}$, but can still be connected to the $5 \mathrm{~V}$ pin to an Arduino without using any logic level converters $[16,17,18,19,20]$.

The automated irrigation system is designed to operate 24/7 and in order for this to be achieved there is a need for constant power supply. Hence, the system is also designed to run solar power which on the long-term is a sustainable and costeffective solution using renewable energy [21, 22, 23, 24, 25, 26]. The system is powered by a battery that is powerful enough to power the system all through the evenings and night when there is no sunlight. The battery is then charged up with during the day using solar panels. This enables the entire automated irrigation system to run independently off-grid without the need for recurring power costs. This is a major advantage for the system which when used on even a larger scale can revolutionize the way we see irrigation farming, making it more efficient and environmentally friendly. The aim of this project was to design and construct a solar powered automated drip irrigation system based on the Arduino microcontroller and cheap wired soil moisture sensors, to automatically monitor soil humidity and moisture determine when the crops require watering by actuating solenoid valves open or close. The introduction of the paper should explain the nature of the problem, previous work, purpose, and the contribution of the paper. The contents of each section may be provided to understand easily about the paper.

\section{METHODOLOGY}

\section{II.I The Sensing Module}

The sensing unit as shown in fig. 1 is responsible for harvesting the moisture content of the soil at a particular time. The system consists of three sensor unit boxes for three crop species and each sensor box consists of a network of five (5) Soil Moisture Sensors, an Arduino UNO Microcontroller (Slave Arduino) and a Nrf24L01+ transceiver. The soil moisture is measured using the Probe-type Soil Moisture Sensor. The sensor gives out a value usually between the range of 420 and 1023 based on its architecture and moisture content. The Sensing Units establishes a wireless serial communication with the Master Arduino (actuating unit) via the Nrf24L01+ communication transceivers. Power is supplied to this unit by a 9 Volts D.C. battery.

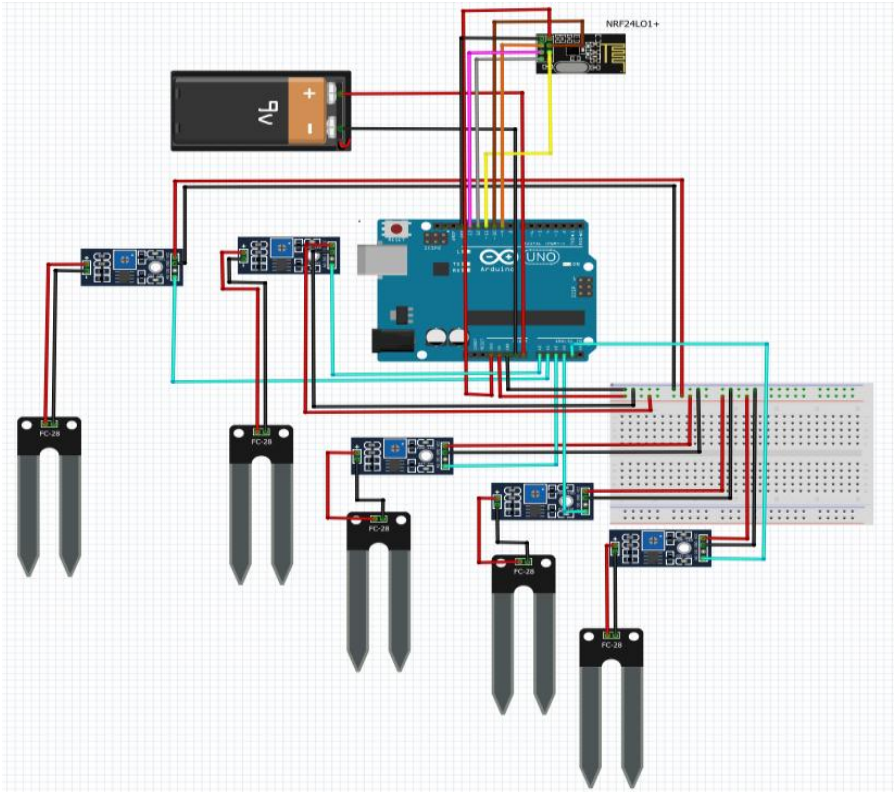

Figure 1: Moisture sensor datalogger circuit schematic.

\section{II.II Soil-Moisture Sensors}

This device is used to approximately determine the moisture content of the soil based on the dielectric constant (soil bulk permittivity) of the soil. Precise water content measurements of the soil are essential for grasping the concepts of chemical as well as organic course in the roots of plants as well as in the vadose zone. The sensors are fifteen in number and provide sensory feedback of soil humidity values to the microcontrollers; the data is analog which should be converted to a range of percentage values. The sensors in use here are cheap wired soil moisture sensors and similar models can be employed through minimal changes to the calibration algorithm in the microcontroller.

\section{II.III Microcontroller}

The Arduino microcontrollers are based on the ATmega328P. It is the 'brain' of the entire project module and are responsible for receiving inputs from sensors, mathematical calculations decision making, and displaying values and status of system components (for instance water pump). The Arduino Uno and Mega microcontrollers were chosen as the controller for this module because of its economic cost, portable size, compactness and ease of programming and interfacing over several other types of controllers as well as modules. The system makes use of three Arduino Uno microcontrollers and One Arduino Mega microcontroller. The Arduino Unos are named 'Slaves' as they simply read analogue inputs from the SMSs, take the average and wirelessly transmit the values to the Arduino Mega. The Mega is termed the 'Master' as it receives the average values from the slaves, compares them with predetermined values in its algorithm, then decides which crop type requires watering by opening the solenoid valves via a relay channel. 


\section{II.IV Nrf24L01 transceivers}

This is essentially a low-cost, powerful but minimal energy requirement transmitting/receiving device which enables wireless communication over a long range for about 150 meters in the absence of barriers (for instance walls) and can be integrated with Arduino family controllers. The transceiver also allows networking between multiple modules for sending and receiving multiple packet data simultaneously.

\section{II.V 8-Channel Relay}

This is an electromagnetically operated device which can operate large voltage switches via smaller voltages. They are implemented where it is essential to operate a circuit by a lowpower signal. The relay is used to operate a device with a higher power rating.

\section{II.VI Solenoid Valve}

This is an electromechanically actuated valve. It is initially in the closed position (i.e. normally closed), and when the circuit is live or current is allowed to flow, the valve opens allowing fluid to flow into a drip irrigation line. There are three solenoid valves for each sub- drip irrigation line.

\section{II.VII Drippers}

This is the main core component that controls the delivery of water to the plant roots. A dripper for water irrigation system has a removable male part with a handle and ridges giving a wandering water stream way to control pressure drop and is held in a smooth walled female container by tabs for brisk expulsion by winding the handle. A bracing part going with holds the dripper by encompassing supply pipe lines of different sizes with an opening there through to get a dripper expansion by methods for a mating lock snare parcel connecting with the internal dividers of the supply pipe line. The male dripper part edges might be made of plastic to permit prepared expulsion of edge divides for changing the direction and dribble rate. The flow rate of the drippers used here are within the 0-70 LPH range.

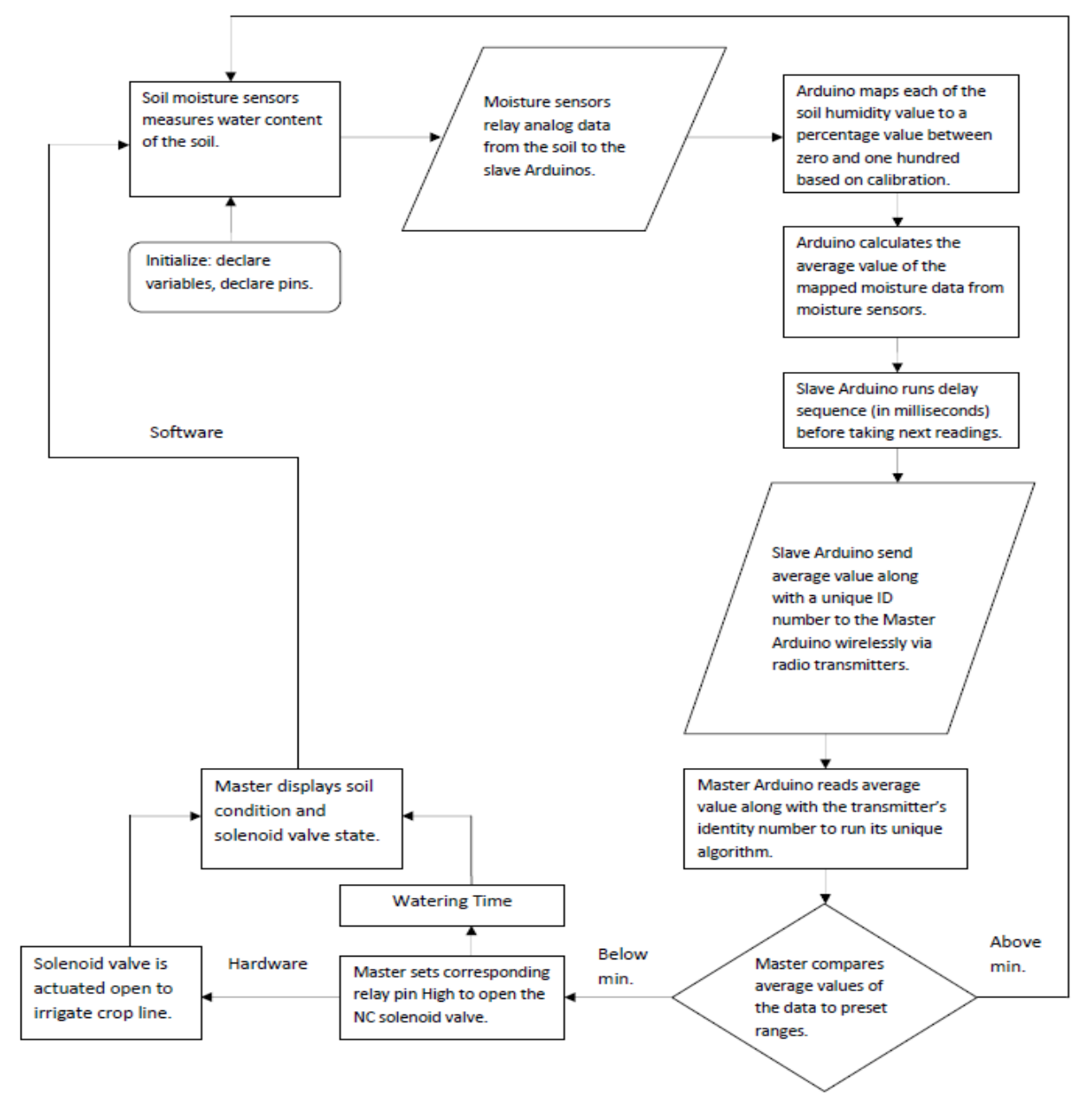

Figure 2: Microcontroller program flowchart. 


\section{II.VIII Electrical Power}

A 160W rated solar panel was used for power supply. A solar panel or Photovoltaic cell is an electrical device used to convert solar energy into electricity via the use of Silicon semiconducting material doped with other semi-conducting elements. The solar panel supplies optimum rated power when used in areas which receive adequate sunlight such as is noticeable in many sub-Saharan African nations. Solar powered drip water system fundamentally increases both family unit salary and dietary admission, especially amid the dry season, and is practical and economical.

\section{II.IX Microcontroller Programming}

The Arduino microcontrollers were programmed using the Arduino compiler. Arduino allows the programmer to write microcontroller code in higher level language like

$\mathrm{C}$ and $\mathrm{C}++$ closer to English rather than in assembly language and upload to an Arduino board allowing the board to control the actions of electronics connected to it. The hardware itself is inexpensive, open source and extensible. The languageArduino $\mathrm{C}$ can be expanded with libraries on the $\mathrm{C}++$ platform. The Arduino compiler converts a $\mathrm{C}$ language to an assembly algorithm which is then uploaded to the microcontroller. Uploading is achieved via a simple 5V USB cord specially designed to transfer data as well as supply power to the microcontroller's $5 \mathrm{~V}$ port. The Arduino hardware is enabled with a flash memory storage facility to hold data such as Sketches, the Static Random-Access memory - SRAM is where variables defined in the sketch are manipulated while the program is running. Finally, the Electronic Erasable Read Only Memory - EEPROM is a memory space where programmers store information for the long-term. It persists when power is turned off or it is cycled.

\section{II.X Circuit Operation}

A flow-chart outlining the main steps in the program is shown in fig 2. The circuit consists of four microcontrollers all connected to one $9 \mathrm{~V} 40 \mathrm{~A}$ battery power source which recharges itself with a $12 \mathrm{~V}$ mono-crystalline solar panel connected to a solar charge controller. The microcontrollers themselves are not physically connected in any other way with each other. Of the four controllers, three are Arduino Unos and the last is an Arduino Mega. Each of the Unos has five wired soil moisture sensors connected to it. The purpose of the Uno is simply to continuously read analog values of soil moisture from the sensors and the three controllers are programmed via calibration to map the readings to a percentage value between zero and one hundred percent, then calculate the mean (average) value and transmit it to the Arduino Mega as a payload data along with a unique number variant for each Uno for its Identification. Each of the four Arduinos has a radio transceiver (NRF24L01+) connected to it for wireless communication.

The Arduino Unos are termed 'slaves' while the Mega is termed the 'Master' controller. The radio transceivers work with pipe addresses unique for each pair of transmitting and receiving communicator. With respect to this, each transmitter on the Unos is programmed to open a unique pipe address for data transmission, with the receiver. Only one pipe address can be open at a time. On the receiver connected to the Mega, it has the three addresses stored and each open at random intervals to receive payload data creating a node network of wireless communication (one-way 3 to 1 ). The purpose of the unique identity number is to allow the programmer set what algorithm to run when data is received as knowledge of the open pipe addresses is not possible. Each Uno is dedicated to measuring moisture content of a particular crop type and various crops have different moisture requirement, thus the importance of the knowledge of the transmitting Arduino to the programmer. Depending on the identity of the transmitter, the Mega is further programmed to run a unique algorithm of moisture content range test for the received data. Based on the range the data falls in, the Soil condition and solenoid valve state is displayed on a $16 \times 2$ LCD module.

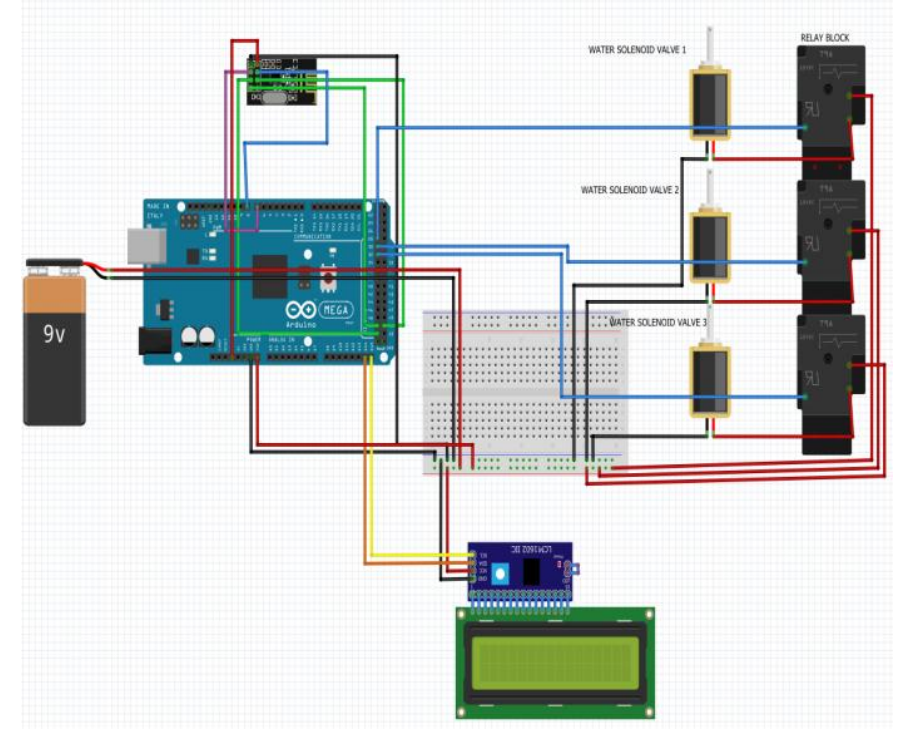

Figure 3: Control Module Schematic.

There are three possible ranges between $0-100 \%$ for the data to fall in;

0\% - X\%: Dry Soil; Valve (A) open.

$\mathrm{X} \%$ - Y\%: Moist Soil; Valve (A) closed.

Y\% - 100\%: Soggy Soil; Valve (A) closed.

Where $\mathrm{X}$ and $\mathrm{Y}$ are varying preset values on the Arduino Mega for each transmitting Uno dedicated to a crop type, while ' $A$ ' refers to the corresponding solenoid valve along the drip line for the transmitting Arduino Uno.

The valves are actuated 'open' by the Mega via an eightchannel relay block. The valves remain open to allow water flow into the dip line and irrigate the crops for a preset time in the code or till the Mega reads a soil state value above the 'Dry Soil' range. 
International Journal of Engineering Research and Technology. ISSN 0974-3154, Volume 13, Number 6 (2020), pp. 1307-1313

(C) International Research Publication House. https://dx.doi.org/10.37624/IJERT/13.6.2020.1307-1313

Stanchion: Most irrigation systems require a mechanism to supply water at the required pressure to the system. The solenoid valves, drippers, as well as the water hoses act as resistance to the flow of water and require a higher potential energy from the incoming fluid flow to operate functionally. With respect to this, the stanchion is placed at a 2-meter height above the ground with the storage tank on it for this purpose. A plastic tank designed for storing liquid was procured. Its volume is 1000 liters based on an estimation of the amount of water required for a month for the species of crops and quantity planted.

Pressure Loss: This shows the mechanics involved in the flow of water from the tank to the emitters. The results of the calculation allow us to design an efficient delivery system and better understand the setup. It supported the decision for the application of a gravity-fed supply system without the requirement of a pump.

\section{Total pressure from the tank:}

Total pressure from the tank at height of 2 meters is represented by $\sigma \times g \times h$

height $=2 m$.

$\mathrm{g}$ is acceleration due to gravity $=9.81 \mathrm{~ms}^{-2}$.

Therefore, total pressure is $1000 \times 9.81 \times 2=19620 \mathrm{~N} / \mathrm{m}^{2}$

\section{Head Loss in pipe:}

$h_{f}=\left(F I V^{2} \mid 2 D g\right)$

Where,

$\mathrm{h}_{\mathrm{f}}$ is the head loss in pipe

$\mathrm{f}$ is the friction factor

1 is the length of pipe

$\mathrm{V}$ is the flow velocity

$\mathrm{D}$ is the diameter of pipe

$\mathrm{G}$ is acceleration due to gravity

Also,

$f=(64 / \operatorname{Re})$

Where, Re is Reynolds number.

$\mathrm{Re}=(\mathrm{VD} / \mathrm{v})$

and $\mathrm{V}$ is the flow velocity

$\mathrm{D}$ is the diameter of pipe

$\mathrm{v}$ is kinematic viscosity

From our experiment with the flow from our tank, we have flow velocity as $1 \mathrm{~m} / \mathrm{s}$

The kinematic viscosity of our fluid (water) is $8.9 \times 10-7 \mathrm{~Pa}$
Diameter of our pipe is $0.01905 \mathrm{~m}$

$\operatorname{Re}=(1 \times 0.01905) /(8.9 \times 10-7)=21404.494$

Friction factor $=(64 / \mathrm{Re})=64 / 21404.494=2.99 \times 10-3$

Head loss $=(2.99 \times 10-3 \times 2 \times 1) /(0.01905 \times 2 \times 9.81)$

Head loss $=0.01599 \mathrm{~m}$

\section{Pressure loss in pipe:}

Also postulated by Darcy,

$\sigma \times g \times \Delta h=\Delta p$

Where,

$\sigma$ represents density of fluid which is $1000 \mathrm{~kg} / \mathrm{m}^{3}$ $\mathrm{g}$ represents acceleration due to gravity.is $9.81 \mathrm{~m} / \mathrm{s}$ $\Delta \mathrm{h}$ represents head loss in pipe which is $0.01599 \mathrm{~m}$ $\Delta \mathrm{p}$ represents pressure loss in pipe which is unknown $\Delta p=1000 \times 0.01599 \times 9.81=156.86 \mathrm{~N} / \mathrm{m}^{2}$ Therefore, pressure loss in the pipe is $156.86 \mathrm{~N} / \mathrm{m}^{2}$

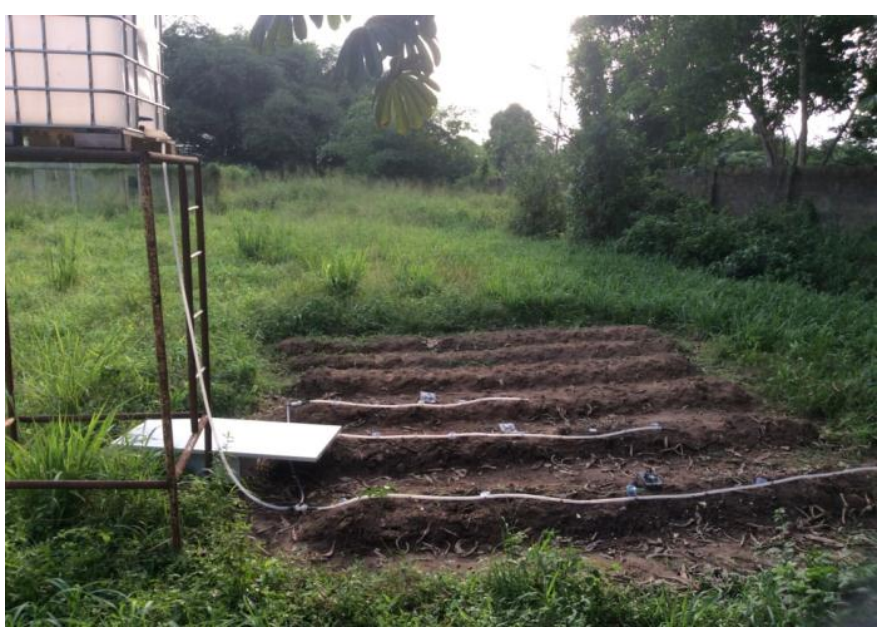

Figure 4: A prototype automated irrigation system.

\section{DISCUSSION}

A water reservoir tank of capacity 1000 liters elevated on a stanchion of height 2 meters above the ground is used to store and supply water at the required pressure via gravity to the drip irrigation system when required, as determined by the microcontrollers which control the solenoid valves. The piping design is made up of a 4-meter-long main drip line connected directly to the tank. Along its length lying horizontally on the floor, are three equally spaced drip sub-lines for three crop rows/ridges, each of which holds ten equally spaced drippers to deliver the water directly to the roots of ten crops. At the junction where the main line connects to each sub-line is a solenoid valve which is actuated as controlled by the Arduino 
microcontroller. Along each drip irrigation sub-line is a sensor box which houses an Arduino Uno microcontroller dedicated to reading analog values of soil humidity from five evenly spaced moisture sensors along a subline.

When the soil humidity sensors read values from the soil, the Arduino Uno is programmed to calibrate the values to a percentage range of values between zero and one hundred. The overall average humidity value is then calculated, and transmitted along with a unique identity number (to distinguish each Arduino Uno from the others) via a radio transmitter NRF24L01+ to the central Master control Arduino Mega. When the Master Arduino reads the Average humidity value and identity number from a particular transmitting Uno, it runs the algorithm unique to the crops the transmitting Uno is monitoring to determine if the soil humidity average value falls within the 'dry soil', 'moist soil', or 'soggy soil' range. If it falls in the 'dry soil' range, the Mega actuates the corresponding solenoid valve open to allow water flow into the sub-line of the transmitting Uno to irrigate the crops for a set amount of time after which it closes. Any other range would keep the valves closed.

\section{CONCLUSION}

Drip method is a method of irrigation used in conserving water usage in agriculture. In drip irrigation process, water is distributed continuously to the crop roots drop by drop. This is essential because it reduces water use and ensures the survival of the crops and avoids damage to crops due to excessive irrigation. A microcontroller-based drip irrigation mechanism has been designed to efficiently run all the activities involved in a drip irrigation system. Water is supplied to the crops in the right quantity and at the required time. The improve system was designed and developed by integrating several hardware and software features has been tested successfully. The designed system was able to determine when exactly the soil of each crop needs water, wirelessly communicate the moisture state of the soil of the different crops to the control module, deliver a controlled amount of water to the root zone of the crops based on the soil moisture state and able to run $24 / 7$ on renewable solar energy which improves crop development and helps in time and cost saving.

\section{ACKNOWLEDGEMENTS}

The authors are grateful to the Management of Covenant University for providing a conducive environment for successful completion of this research work.

\section{REFERENCES}

[1] G., Kumar, Research paper on water irrigation by using wireless sensor network. International Journal of Scientific Research Engineering and Technology (IJSRET). (2014) 3-4.

[2] M. F., Leroux, and G. V., Raghavan, Design of an automated irrigation system. McGill University
Canada, research paper. (2005).

[3] A., Tyagi, N., Gupta, J. P., Navani, M. R., Tiwari, and M. A., Gupta, Smart irrigation system. International Journal for Innovative Research in Science and Technology. 3(10) (2017).

[4] M., Umeh, M., Njideka, S. O., Okafor, and F. C., Agba, Intelligent microcontroller-based irrigation system with sensors. American Journal of Computer Science and Engineering. 2(1) (2015) 1-4.

[5] M., van Iersel, R. M., Seymour, M., Chappell, F., Watson, and S., Dove, Soil Moisture Sensor-Based Irrigation Reduces Water Use and Nutrient Leaching in a Commercial Nursery. 54(5) (2001) 28-34.

[6] S. R. N., Reddy, Design of remote monitoring and control system with automatic irrigation system using GSM-bluetooth. International Journal of Computer Applications. 47(12) (2012).

[7] I., Gautam, and S. R. N., Reddy, Innovative GSM bluetooth based remote controlled embedded system for irrigation. International Journal of Computer Applications. 47(13) (2012).

[8] M., Asadullah, and K., Ullah, Smart home automation system using Bluetooth technology. In 2017 International Conference on Innovations in Electrical Engineering and Computational Technologies (ICIEECT), IEEE. (2017) 1-6

[9] J. M., Sieminski, U.S. Patent No. 6,823,239. Washington, DC: U.S. Patent and Trademark Office. (2004).

[10] Z., Feng, Research on water-saving irrigation automatic control system based on internet of things. In 2011 International Conference on Electric Information and Control Engineering, IEEE. (2011) 2541-2544.

[11] K., Kansara, V., Zaveri, S., Shah, S., Delwadkar, and K., Jani, Sensor based automated irrigation system with IOT: a technical review. International Journal of Computer Science and Information Technologies. 6(6) (2015) 5331-5333.

[12] A. R., Al-Ali, M., Qasaimeh, M., Al-Mardini, S., Radder, and I. A., Zualkernan, ZigBee-based irrigation system for home gardens. In 2015 International Conference on Communications, Signal Processing, and their Applications (ICCSPA'15), IEEE. (2015) 1-5.

[13] R. R., Rewatkar, S. B., Hedau, S. R., Mudliyar, M. A., Dharmik, and P. A., Bhede, Automation in drip irrigation using embedded control system. International Journal of Science, Engineering and Technology Research (IJSETR). 5(4) (2016) 860863.

[14] J., Srirampavan, Smart secured real time agriculture monitoring system. International Journal of Engineering and Technology. 7(3.6) (2018) 281-285 
[15] Azeta, J., Bolu, C. A., Alele, F., Daranijo, E. O., Onyeubani, P., \& Abioye, A. A. (2019, December). Application of Mechatronics in Agriculture: A review. In Journal of Physics: Conference Series (Vol. 1378, No. 3, p. 032006). IOP Publishing.

[16] D., Sunehra, Web Based Smart Irrigation System Using Raspberry PI. International Journal of Advanced Research in Engineering and Technology. 10 (2) (2019) 55-64.

[17] Z. Y., Shi, J. P., Gai, D. H., Wang, and Z. J., Zhang, A new kind of high-speed wireless RF transceivernRF24L01 and its application [J]. International Electronic Elements. 8 (2007) 42-44.

[18] Z., Chen, C., Hu, J., Liao, and S., Liu, Protocol architecture for wireless body area network based on nRF24L01. In 2008 IEEE International Conference on Automation and Logistics, IEEE. (2008) 3050-3054.

[19] Z. P., Liu, and G. L., Zhao, Short-range wireless data transmission based on nRF24L01 [J]. Applied Science and Technology. 3 (2008).

[20] H., Li, S., Song, and J. J., Zhou, Design of wireless data transceiver system based on ARM and nRF24L01 [J]. International Electronic Elements. 12 (2008)

[21] Bolu, C. A., Azeta, J., Alele, F., Daranijo, E. O., Onyeubani, P., \& Abioye, A. A. (2019, December). Solar Powered Microcontroller-based Automated Irrigation System with Moisture Sensors. In Journal of Physics: Conference Series (Vol. 1378, No. 3, p. 032003). IOP Publishing.

[22] Q., Jia, D., Wang and Z., Zhang, Wireless data transmission system based on nRF24L01 [J]. Modern Electronics Technique. 7 (2008).

[23] A. R., Al-Ali, S., Rehman, S., Al-Agili, M. H., AlOmari and M., Al-Fayezi, Usage of photovoltaics in an automated irrigation system. Renewable energy. 23(1) (2001) 17-26.

[24] J., Uddin, S. T., Reza, Q., Newaz, T., Islam and J. M., Kim, Automated irrigation system using solar power. In 2012 7th International Conference on Electrical and Computer Engineering, IEEE. (2012) 228-231

[25] S., Harishankar, R. S., Kumar, K. P., Sudharsan, U., Vignesh and T., Viveknath, Solar powered smart irrigation system. Advance in Electronic and Electric Engineering. 4(4) (2014) 341-346.

[26] M. A., Murtaza, M., Sharma, R., Yadav, R., Chaudhary and K., Rastogi, Solar Powered Automatic Irrigation System. International Journal of Engineering Science and Computing (IJESC). 7(4) (2017) 10719-10722. 